\title{
Social Interaction and Urban Sprawl
}

\author{
by \\ Jan K. Brueckner \\ Department of Economics \\ University of California, Irvine \\ 3151 Social Science Plaza \\ Irvine, CA 92697, USA \\ e-mail: jkbrueck@uci.edu \\ and \\ Ann G. Largey \\ Dublin City University Business School \\ Dublin 9, Ireland \\ e-mail: alargey@uci.edu
}

October 2006

\begin{abstract}
Various authors, most notably Putnam (2000), have argued that low-density living reduces social capital and thus social interaction, and this argument has been used to buttress criticisms of urban sprawl. If low densities in fact reduce social interaction, then an externality arises, validating Putnam's critique. In choosing their own lot sizes, consumers would fail to consider the loss of interaction benefits for their neighbors when lot size is increased. Lot sizes would then be inefficiently large, and cities excessively spread out. The paper tests the premise of this argument (the existence of a positive link between interaction and density) using data from the Social Capital Benchmark Survey. In the empirical work, social interaction measures for individual survey respondents are regressed on census-tract density and a host of household characteristics, using an instrumental-variable approach to control for the potential endogeneity of density.
\end{abstract}




\title{
Social Interaction and Urban Sprawl
}

\author{
by
}

\author{
Jan K. Brueckner and Ann G. Largey
}

\section{Introduction}

Urban sprawl has become a hot policy issue in the United States over the last decade. Critics of sprawl argue that urban expansion leads to an undesirable sacrifice of farmland along with a loss of amenity benefits from open space on the urban fringe. The longer commutes caused by sprawl are thought to create excessive traffic congestion and air pollution, and sprawl's suburban focus is viewed as depressing the incentive to revitalize decaying downtown areas. Finally, commentators such as Putnam (2000) argue that the low-density suburban lifestyle associated with sprawl reduces social capital, leading to a less-healthy society. ${ }^{1}$

In response to these concerns, local governments have adopted a wide range of antisprawl measures, including urban growth boundaries (UGBs) and other related zoning policies, public land-purchase programs designed to protect vacant land, and price-based mechanisms such as impact fees that are designed to slow the pace of development. See Brueckner (2001) for an overview of such policies; Nechyba and Walsh (2005) and Glaeser and Kahn (2006) offer further discussion.

In appraising the attack on sprawl, Brueckner $(2000,2001)$ argues that criticism of urban spatial expansion is only justified in the presence of market failures or other distortions, which bias the normal expansionary effects of population and income growth in an upward direction. Such distortions might include a failure by developers to account for the amenity value of fringe open space in their development decisions, and the failure of commuters to account for the congestion externalities they generate. The first failure leads to excessive conversion of agricultural land, while the second leads to overly long commute trips, and both effects imply excessive spatial expansion of cities. The remedy for the first failure would be higher tax on urban development, designed to charge the developer for lost open-space amenities, and the remedy for the second would be congestion pricing of roadways. ${ }^{2}$ 
The purpose of the present paper is to consider a different market failure, one associated with social interaction, and to assess whether this failure is empirically relevant as a basis for criticism of urban sprawl. The starting point of the analysis is the above allegation that sprawling, low-density development weakens social capital and thus the level of social interaction. While such an effect, by itself, is not the basis of a proper anti-sprawl argument, the case is different if the nexus between social interaction and density involves an externality.

To understand the argument, suppose that people value social interaction, ${ }^{3}$ and that the extent of interaction in a neighborhood is an increasing function of the area's average population density. By putting people in close proximity, high average density could plausibly spur interaction among them. Average density in a particular household's neighborhood depends, in turn, on its own consumption of living space as well as the space consumption levels of its neighbors.

In choosing space consumption, a household would consider the direct gains from having more room, along with the negative effect on the social interaction it enjoys, caused by the drop in neighborhood population density due to its larger residence. But the household would fail to consider the external effects of consuming more space, which consist of less social interaction for all its neighbors, again a consequence of lower neighborhood density. The result is a density externality, which makes space consumption inefficiently high for each household, an effect that translates into an inefficiently low level of population density for the neighborhood. Because this argument can be replicated city-wide, it implies inefficiently low density throughout the urban area, and thus inefficient spatial expansion of the entire city. Thus, the existence of a density externality based on social interaction can provide another basis for criticism of urban sprawl. ${ }^{4}$

A simple model developing this idea is presented in section 2. But the main goal of the paper is to appraise the empirical relevance of an anti-sprawl argument based on social interaction. This task requires an empirical test of the underlying hypothesis, which asserts that social interaction is an increasing function of population density. If this hypothesis is validated, then the existence of a density externality follows naturally, leading to the conclusion that the spatial expansion of cities is excessive. 
The paper uses data from the Social Capital Benchmark Survey, which provides a number of different measures of social interaction for individual survey respondents in a national sample, while identifying the census tract where each respondent lives. With the tract identity known, population density can be computed for each survey respondent's "neighborhood." This density measure is then used as a right-hand variable in a regression explaining social interaction, which also includes a variety of demographic indicators as covariates. The social interaction measures that are used include a count of the respondent's number of close friends, an indicator of whether the respondent has someone to "confide in," and related variables.

Similar exercises have been carried out by Glaeser and Gottlieb (2006) and Borck (2006), focusing more broadly on the determinants of social capital, which includes political involvement and civic engagement in addition to measures of social interaction. Glaeser and Gottlieb relate their social capital indicators to suburban vs. city residence, and Borck investigates how social capital is affected by city size.

In addition to its narrower focus, the present paper differs from both these studies by measuring the key determinant of interaction (here, density) at a disaggregated, census-tract level. This approach raises an econometric issue that was not a major factor in the previous studies. In particular, with the census tract of residence being a choice variable of the survey respondent, it cannot be treated as an exogenous determinant of social interaction. For example, if social interaction indeed rises with density, then an unusually interactive person (one with unobservable characteristics highly favorable to interaction) might select a dense census tract in seeking a congenial place of residence. With this behavior, density would be positively correlated with the error term in a social-interaction regression, leading to a biased and inconsistent estimate of its coefficient. Such correlation could also be generated by other kinds of location behavior.

The empirical work uses an instrumental-variables approach to handle this endogeneity problem. Since none of the demographic variables available in the survey can be plausibly excluded as a determinant of interaction, different instruments were sought. The chosen variables are measures of population density at a more-aggregated level: the first is population density for the urbanized area containing the census tract, and the second is density for the tract's 
MSA. These average density measures are strong determinants of population densities in individual census tracts. Their use, however, presumes that the endogeneity problem involving tract density does not extend to the metro level. In other words, while people may self-select across tracts in endogenous fashion, their choice of a metro area (and hence metro density) is presumed to be unrelated to unobservable characteristics affecting social interaction. ${ }^{5}$

Following the theoretical discussion in the next section, the data and variables are described in section 3, and empirical findings are presented in section 4. Section 5 offers conclusions.

\section{Modeling the Density Externality}

A density externality can be modeled in the context of a monocentric city, as seen in Fujita (1989, Ch. 7). However, a simpler spatial structure comes from assuming that individual land parcels are arbitrarily clustered together in space without the attractive force of a central business district. For further simplification, suppose that people consume land directly, with housing capital suppressed, and let consumer $i$ 's land consumption (lot size) be denoted $q_{i}$. The spatial area of the city, denoted $A$, is then found by adding the individual lot sizes, so that $A=\sum_{j=1}^{n} q_{j}$, where $n$ is the number of consumers.

In addition to lot size, consumer $i$ cares about non-land consumption expenditure, denoted $c_{i}$, and social interaction, denoted $I_{i}$. Preferences, assumed for simplicity to be the same for all consumers, are given by the well-behaved utility function $U\left(q_{i}, c_{i}, I_{i}\right)$. For simplicity, the level of social interaction is also assumed to be uniform, and it depends on the city's average population density, which equals $n / A$. While under a more realistic approach, $I_{i}$ might depend only on the average densities of the lots near $i$ 's, this change would only introduce inessential complications in the model. As seen below, however, this local approach to measurement of density is followed in the empirical work.

Given the above assumptions, the level of interaction can be written $I_{i}=f(n / A)$, with $f$ being a smoothly increasing function under a positive density effect (so that $\left.f^{\prime}>0\right){ }^{6}$ For completeness, however, it is helpful to also consider the possibility that a higher density reduces interaction, as assumed by Fujita (1989). ${ }^{7}$ In this case, $f(\cdot)$ is a decreasing function, with $f^{\prime}<0$. 
Land is assumed to be available at a fixed opportunity $\operatorname{cost} \bar{r}$, so that consumer $i$ 's budget constraint is $c_{i}+\bar{r} q_{i}=y$, where $y$ is the common level of income. Eliminating $c_{i}$, the objective function for consumer $i$ is then given by

$$
U\left[y-\bar{r} q_{i}, q_{i}, f\left(n / \sum q_{j}\right)\right] .
$$

The consumer chooses $q_{i}$ to maximize (1), taking the lot sizes of other consumers, $q_{k}, k \neq i$, as parametric. The first-order condition is

$$
-\bar{r} U^{c}+U^{q}-U^{I} \frac{n f^{\prime}}{\left(\sum q_{j}\right)^{2}}=0,
$$

where superscripts denote partial derivatives. Since consumers are identical, the resulting Nash equilibrium is symmetric, with $\sum q_{j}=n q$, where $q$ is the common lot size. Rearranging and imposing symmetry, (2) becomes

$$
\frac{U^{q}}{U^{c}}=\bar{r}+\frac{f^{\prime}}{n q^{2}} \frac{U^{I}}{U^{c}} .
$$

If the density effect is positive, this condition says that lot size is optimal when the consumption benefit from a marginal increase in $q$, given by the MRS term on the left, is equal to the money cost per unit of land, $\bar{r}$, plus a cost from reduced interaction, as captured by the last term. This cost is equal to the marginal benefit of interaction (the MRS term) times the reduction in the interaction enjoyed by the consumer when his lot size increases (the $f^{\prime} / n q^{2}$ term).

Because consumers ignore the density externality, the equilibrium characterized by (3) is inefficient. The social optimum can be found by imposing symmetry at the outset and maximizing the utility of a representative consumer. The objective function is then $U[y-$ $\bar{r} q, q, f(1 / q)]$, where density is given by $n / n q=1 / q$. The first-order condition for this problem is

$$
\frac{U^{q}}{U^{c}}=\bar{r}+\frac{f^{\prime}}{q^{2}} \frac{U^{I}}{U^{c}},
$$


where $f^{\prime} / q^{2}$ gives the loss of interaction when lot size is increased simultaneously for all consumers. Since the $1 / n$ factor in the last term of (3) is smaller than unity, it follows that the interaction-cost term in (4) is larger than the corresponding term in (3). As a result, the MRS on the left-hand side is larger at the social optimum than at the Nash equilibrium, which will tend to make the socially optimal lot size, denoted $q^{*}$, smaller than the equilibrium size, denoted $q^{e}$. This conclusion is assured, for example, if preferences are additively separable in $I$, so that the MRS term on the left of (3) and (4) is independent of the level of social interaction.

Since $q^{e}>q^{*}$, it follows the equilibrium spatial size of the city, denoted $A^{e} \equiv n q^{e}$, is larger than the optimal size, $A^{*} \equiv n q^{*}$. Thus, the equilibrium is characterized by inefficient spatial expansion of the urban area, providing a basis for criticism of urban sprawl.

The social optimum can be supported by a tax per unit of land consumption, denoted $t$, which would appear as an extra term on the RHS of the equilibrium condition (3). This tax must make (3)'s RHS equal to the RHS of (4), evaluated at the optimum. Equating the two expressions, the tax is given by

$$
t=\frac{(n-1) f^{* \prime}}{n q^{* 2}} \frac{U^{i *}}{U^{c *}},
$$

where the asterisks on $f$ and the marginal utilities indicate that these expressions are evaluated at the social optimum. Recalling from above that the expression in (5), absent the $n-1$ factor, gives one consumer's loss from lower interaction when his lot size increases, it follows that the tax serves to charge the consumer for the equivalent losses suffered by his $n-1$ neighbors. With the externality thus internalized, the equilibrium under taxation is efficient.

By contrast, if the density effect is negative, with $f^{\prime}<0$, then the second term in (4) is negative, and $q^{e}<q^{*}$. Individual lot sizes are thus too small, and the city is insufficiently spread out rather than too large. In this case, $t$ in (5) is negative, indicating that land consumption should be subsidized, not taxed, to support the social optimum.

When the density effect is positive, an urban growth boundary can be used to generate the optimum. An upper bound of $A^{*}$ would be imposed on the spatial size of the city via zoning regulations, and this restriction in land supply would cause the land price to rise above 
its opportunity cost. The new equilibrium would be characterized by (3), with $\bar{r}$ replaced by an endogenous land rent $r$, along with the condition $\sum q_{j}=A^{*}$. It is easy to see that the equalities $q=q^{*}$ and $r=\bar{r}+t$ hold in equilibrium.

By contrast, a different type of quantity restriction is needed to address the inefficiency caused by a negative density effect. In this case, a minimum-lot-size regulation, which requires $q \geq q^{*}$, must be imposed.

The preceding analysis shows that, if social interaction is an increasing function of population density, then the uncoordinated choices of consumers will lead to lot sizes that are inefficiently large and a city that takes up too much space. The remainder of the paper is devoted to testing the premise of this argument, namely, that interaction increases with density.

\section{Data and Variables}

The data are drawn from the Social Capital Benchmark Survey, which was carried out by the Saguaro Seminar at Harvard's Kennedy School of Government and is disseminated by the Roper Center for Public Opinion Research at the University of Connecticut (www.roper. uconn.edu). The survey posed hundreds of social-capital questions to a nationwide sample of over 30,000 respondents. A restricted version of the data identifies each respondent's census tract, allowing accurate measurement of local population density. Given the focus on urban sprawl, attention is restricted to those respondents living in the urbanized-area portions of MSAs (thus excluding rural areas), which reduces the sample size to 14,827 individuals. Because most of the social interaction variables, which are described next, have a small number of missing values, the effective sample sizes are usually slightly smaller than this number.

The analysis focuses on variables narrowly measuring social interaction, not including broader indicators of social capital. The variables, whose full definitions are given in Table 1 along with summary statistics, fall into two sets. The first set consists of variables measuring the extent of the respondent's neighborhood contacts and friendships. NEISOC measures how often the respondent socializes with neighbors; NEITALK is a dummy variable indicating whether this interaction occurs at least once a week; CONFIDE counts the number of people the respondent can confide in; FRIENDS counts the number of close friends; FRNDHNG 
measures the frequency of "hanging out" with friends in a public place; FRNDHOM measures the frequency with which friends are invited to the respondent's home.

The second set of variables measures the respondent's group involvement. NEICOOP is a dummy indicating cooperation with neighbors to get something fixed or improved; GRPHOB is a dummy indicating membership in a hobby-oriented club; CCLUBMET counts the frequency of attendance at any club meetings over the previous twelve months; GRPINVLV counts the number of formal non-church groups to which the member belongs.

The various social-interaction measures are used as dependent variables in separate regressions. In addition to tract-level population density, which is measured in log form and denoted LNPDEN_TRACT, many demographic covariates are used in these regressions. While full details and variable names are listed in Table 1, these variables include the measures of the respondent's sex, age, race, income, education, region of residence, and marital, employment and citizenship status. Other variables capture the presence of children in the household and whether the respondent has lived in the area for more than 5 years. While the effects of many of these variables on social interaction are hard to predict a priori, marriage (or living with a partner) might lead to more interaction given that couples can benefit from one another's acquaintances. In addition, since many adult social bonds are made through child-related activities, the presence of children should raise the level of interaction. Since long-time residents have had more opportunity to build social linkages, they should exhibit higher interaction than recent arrivals. Lacking social connections at work, unemployed respondents would be expected to interact less than their employed counterparts. Since non-citizens may not be well integrated into U.S. society, they may engage in less social interaction than citizens.

It could be argued that marital status (and thus ultimately the presence of children) depends on the interactive tendencies of an individual, with weak interactors less likely to become married. This view suggests that MAR_PART and the two KIDS variables could be viewed as endogenous, making them inappropriate as right-hand variables in an equation explaining interaction. To address this possibility, specifications without these variables are also estimated, with the results reported following presentation of the main estimates. The HOMEMAKER variable is also dropped in these equations. 
As indicated above, the instruments for tract population density are the log of average density for the urbanized area containing the tract (LNPDEN_UA), and the log of average density for the tract's MSA (LNPDEN_MSA). While urbanized-area density may be most relevant as a determinant of the densities of individual census tracts, all of which are in urbanized areas, MSA density provides additional information. In particular, holding LNPDEN_UA fixed, MSA density helps to capture population densities in the rural portions of an MSA, outside its urbanized areas. This role can be seen in Table 1, which reveals that MSA density has a lower sample mean than urbanized-area density, reflecting the rural component. Rural density, in turn, is a good predictor of the minimum density in the urbanized area, which is achieved at the urban fringe. Thus, information on rural density (via LNPDEN_MSA) and average density for the urbanized-area pins down two points on the area's spatial distribution of population densities. As a result, use of both variables as instruments seems warranted. For comparison purposes, however, the results from a model that uses LNPDEN_UA by itself as an instrument are also discussed following presentation of the main results. The number of urbanized areas represented in the sample is 308, and only a few of these areas belonged to a common MSA.

When the social interaction measure is a binary variable, the equation is estimated using the maximum-likelihood version of Stata's IVPROBIT routine. This routine jointly estimates a probit regression and a linear equation determining LPDEN_TRACT. For the continuous dependent variables, the equations are estimated via two-stage least squares. In presenting the estimates, the results of diagnostic tests related to the tract-density endogeneity issue are also reported.

\section{Empirical Findings}

\subsection{First-stage regression}

The results of the first-stage regression used in the 2SLS estimations are shown in Table 2. ${ }^{8}$ Because the key population density covariates are constant within urbanized areas, the coefficient standard errors in the regression are adjusted using a cluster correction. The results show that average urbanized-area and MSA population densities are both significant deter- 
minants of individual tract densities, suggesting that use of both variables as instruments is appropriate. The coefficients are both less than one, indicating that tract densities respond only partially to an increase in the level of aggregate density. Note also that the urbanized-area density coefficient is larger, showing a stronger tract density response to the more-localized aggregate measure.

The results also show that tract density is monotonically decreasing in household income, with the income-class coefficients becoming increasingly negative as the class rises. These results confirm the well-known tendency of higher-income households to seek suburban locations. Households containing married couples and those with children also live in less-dense tracts, and other things equal, households with older heads follow the same pattern. But a higher education level for the survey respondent has the opposite effect, pulling the household toward denser census tracts. Unemployed respondents live in dense tracts, while U.S. citizens show the opposite pattern. Finally, Black, Hispanic and Asian respondents tend to reside in denser census tracts than non-minority households.

\subsection{Results for friendship-oriented variables}

Results for the friendship-oriented social-interaction variables are presented in Table 3. Panel A of the table shows 2SLS results with NEISOC, a continuous measure, as the dependent variable. Notably, the table shows that the coefficient on tract density is negative and significant, indicating that the frequency of interaction with neighbors is lower in high-density census tracts. This finding contradicts the main hypothesis, which says that such interaction should increase with tract density.

The signs of some of other estimated coefficients match the expectations discussed above. Interaction with neighbors is more frequent when the respondent is married (or living in a partnership), when children are present, and when the respondent is a citizen. The coefficient of LIVG5, while positive, is not significant, indicating no effect of long-time residence in a neighborhood. Unemployed status also has no effect, but being retired increases the respondent's interaction with neighbors. Among variables whose effects were hard to predict, increases in age, income, and education lead to more frequent interaction, while Black and Hispanic households show less interaction than non-minority respondents. The regional coeffi- 
cients show that, relative to the omitted Pacific region, interaction with neighbors is stronger in the west-central part of the country, which corresponds to the Plains states. Finally, the test for endogeneity of the tract density measure suggest that this variable is indeed endogenous, and the overidentification J-test shows that the instruments are valid.

Panel B of Table 3 shows IVPROBIT results using the binary NEITALK measure as dependent variable. This variable, which indicates that the respondent interacts with neighbors at least once a week, is a less-precise measure than NEISOC. Apparently because of this difference, the tract-density coefficient, while still negative, is now insignificant. The signs and significance of the remaining coefficients mostly follow the pattern in panel A, except that none of the income coefficients is significant. The Wald test rejects exogeneity of tract-density. ${ }^{9}$

Panel $\mathrm{C}$ of the table shows 2SLS results when CONFIDE is the dependent variable. The tract-density coefficient is negative and significant, indicating that respondents living in dense census tracts have fewer confidants. Once again, this result contradicts the hypothesis of stronger interaction in denser areas. While the effects of income, education, minority status, retirement, and citizenship match those in the NEISOC equation, marriage and children now have significantly negative coefficients. Apparently, marriage and children increase superficial contacts with neighbors, but reduce the formation of strong outside bonds by fostering an inward orientation. While panel A showed that older respondents interact more with their neighbors, panel $\mathrm{C}$ shows they have fewer confidants up to the quadratic minimum of 51 years, beyond which the age effect turns positive. Also, residence outside of the Pacific region mostly reduces the number of confidants, in contrast to the findings for neighbor interaction. Finally, male respondents have fewer confidants than do females, and unemployment now has a significantly negative effect. While the endogeneity test now cannot reject exogeneity of tract density, the overidentification J-test nevertheless indicates validity of the instruments.

Panel D shows 2SLS results when FRIENDS is the dependent variable. The tract-density coefficient is again negative and significant, indicating that higher tract density reduces the number of friends, which again contradicts the main hypothesis. The effects of age, marriage, children, income, education, minority status, retirement, and unemployment match those in

panel C, but the sex effect is now reversed, with males having more friends than females. ${ }^{10}$ 
Long-time neighborhood residence shows its first significant impact, raising the number of friends. The non-Pacific regional coefficients are mostly negative, but residence in the westnorth-central regional raises the number of friends. Both diagnostic tests are satisfactory.

Panel E shows 2SLS results when FRNDHNG is the dependent variable. The tract-density coefficient, while negative, is now insignificant. The effects of age, marriage, children, income, education, minority status, retirement, and long-time neighborhood residence match those in panel D, but the male coefficient is now significantly negative. ${ }^{11}$ Evidently, while male respondents have more friends, they spend less time hanging out with them in public places than do females. Regional impacts are again mixed, but the effect of unemployment is no longer significant. Exogeneity of tract density is rejected, but the J-test now rejects the overidentifying restrictions. Therefore, there are grounds for questioning the suitability of the instruments for this equation, despite their good performance in the other regressions.

Panel F of Table 3 shows 2SLS results when FRNDHOM is the dependent variable. The tract-density coefficient is again negative but now significant, indicating that respondents invite friends to their homes less frequently in denser census tracts. The other results mostly match those in panel E, except that the male coefficient is insignificant. ${ }^{12}$ The diagnostic tests show the same pattern as in panel E.

Table 3 also shows the tract-density coefficients when the various equations are estimated without instrumental variables, using either OLS or regular probit. As can be seen, the density coefficients are insignificant in the non-IV case in the NEISOC, CONFIDE, FRIENDS, FRNDHOM equations, becoming significantly negative when IV estimation is used. By contrast, the non-IV coefficients are significantly positive in the NEITALK and FRNDHNG equations, while IV estimation leads to coefficients that are negative and insignificant. These comparison suggest that, for each equation, IV methods eliminate an upward bias in the non-IV estimates. This conclusion, in turn, suggests that tract density is positively correlated with the error term in each equation, indicating that individuals whose unobservable attributes favor interaction tend to reside in high-density census tracts. Note that, while this locational tendency is the one predicted above, the earlier rationale for it is now absent. In other words, since interaction decreases rather than increases with density, interactive individuals sacrifice something by 
locating in dense tracts and therefore must have another reason to do so.

Note that, while the positive and significant non-IV coefficients in the NEITALK and FRNDHNG equations would ordinarily be viewed as confirmation of the Putnam hypothesis, the IV results show that these results are spurious, being the consequence of sorting by individuals across neighborhoods. In other words, the apparent tendency of interaction-prone individuals to locate in dense neighborhoods leads to a positive correlation between density and interaction, as reflected in the non-IV estimates. Controlling for this locational endogeneity, the IV results show that, if a given individual (with a particular unobservable propensity to interact) were relocated from a dense to a less dense census tract, the level of interaction for this person would rise, not fall.

Summing up, the results in Table 3 strongly contradict the main hypothesis, showing that social interaction tends to be weaker, not stronger, in high-density census tracts. While a positive density effect might make sense given that people living in close proximity should find interaction easier, the data disconfirm this logic. Possible reasons for the contrary findings are discussed in section 4.5 below.

\subsection{Results for group-involvement variables}

Group involvement measures another dimension of social interaction, and Table 4 presents results for the four variables in this set. Panel A of the table shows IVPROBIT results with NEICOOP as the dependent variable. Note that, because of a large number of missing NEICOOP values, the sample size for this estimation is only 7316. The tract-density variable is positive but insignificant, indicating no effect of density on the likelihood of cooperating with neighbors. But cooperation increases with age, marriage, the presence of children, income, education, citizenship, long-time residence, and the respondent's status as a homemaker. ${ }^{13}$ Interestingly, black respondents are more likely to cooperate with neighbors than non-minority households, although the Hispanic and Asian coefficients are insignificant. Cooperation tends to be more likely outside the Pacific region. The Wald test cannot reject exogeneity of tract density. ${ }^{14}$

Panel B of Table 4 shows IVPROBIT results with GRPHOB as the dependent variable. The tract density coefficient is significantly negative, indicating that membership in a hobby- 
oriented club is less likely in a dense census tract. This finding again contradicts the main hypothesis. Club membership is higher for males and rises with age, income, education, retirement and citizenship, but falls with marriage and the presence of children. ${ }^{15}$ The coefficients of the race and regional variables are now uniformly insignificant. Exogeneity of tract density is rejected by the Wald test. 16

Panel C shows 2SLS results with CCLUBMET as the dependent variable. The tractdensity coefficient is again negative, indicating that respondents living in dense census tracts attend relatively few club meetings, again contradicting the main hypothesis. While the effects of income, education, marriage, the presence of young children, education, retirement, and citizenship are the same as in panel B, the presence of older children raises the frequency of club attendance (perhaps a Boy Scout effect). In addition, males attend fewer meetings, age and unemployment now have negative impacts, and long-time residence has a positive effect. ${ }^{17}$ Regional effects remain absent, and the diagnostic tests are satisfactory.

Panel D shows 2SLS results with GPRINVLV as the dependent variable. A negative coefficient again emerges for tract density, showing that respondents in dense areas belong to relatively few non-church groups. While the effects of income, education, the presence of older children, and citizenship remain the same, the results show higher group membership for black and Hispanic respondents and lower membership for Asians. Given the insignificant racial effects for hobby-oriented club membership, this effect is apparently capturing membership effects for other types of groups. Respondents who are unemployed or are homemakers also belong to fewer groups, while sex, marriage, young children, and long-time residence have no effect. Regional effects are again absent, and the diagnostic tests are satisfactory.

Table 4 again shows the tract-density coefficients from non-IV regressions, and they mostly show the same pattern as in Table 3. In particular, the non-IV GRPHOB, CCLUBMET, GRPINVLV density coefficients are all insignificant, while IV estimation leads to coefficients that are significantly negative. Although both NEICOOP density coefficients are insignificant, these other results suggest that IV estimation tends to eliminate an upward bias in the non-IV coefficients, indicating a positive correlation between tract density and the error term.

Summing up, the estimates provide the same message as the results for the friendship- 
oriented interaction measures. Group involvement tends to be weaker, not stronger, in highdensity census tracts, contradicting the main hypothesis.

\subsection{Results for other specifications}

Table 5 shows the estimated tract-density coefficients for two additional specifications. The first column shows the consequences of dropping average MSA density as an instrumental variable, using urbanized-area density as a single instrument. By comparison with the results in Tables 3 and 4, it can be seen that, with the exception of the FRIENDS density coefficient, which is only significant at the 10 percent level, the set of significant coefficients is unaffected by use of the single instrument. In addition, the magnitudes of most density coefficients change only slightly, although the FRNDHNG and FRNDHOM coefficients show nontrivial changes. The coefficients for the other covariates, which are not reported, exhibit little change between the two specifications.

The second column of Table 5 shows the consequences of dropping PART_MAR, HOMEMAKER and the KIDS variables as covariates, on the grounds of potential endogeneity. While the coefficient signs remain the same, estimated magnitudes show more-substantial changes than in column one, and two previously significant density coefficients (in the CONFIDE and FRIENDS equations) now are significant only at the 10 percent level. However, the previously insignificant NEITALK coefficient is now nearly significant at the 5 percent level. The estimate coefficients for most of the other covariates are not greatly affected by this change in specification.

Overall, the results in Table 5 show that the main finding of the paper, density's negative effect on interaction, is reasonably robust to these two changes in the specification of the model.

In addition to considering these other specifications, it is useful to compare the present results to selected findings from Gottlieb and Glaeser (2006) and Borck (2006). These papers focus on broad sets of social-capital measures, but a few of their regressions involve socialinteraction measures like the present ones. Using a survey variable indicating whether the respondent entertains friends at home, Glaeser and Gottlieb (2006) present a regression showing that such behavior is less likely in cities than in suburbs. However, this result, which is consistent with present findings, disappears in regressions for the period after 1990. Borck's 
results show that a survey respondent's number of friends is unaffected by city size, while the level of interaction with friends is greater in large cities. With a positive correlation between density and city size, this latter result appears to contradict the present findings. ${ }^{18}$

\subsection{Why is the density effect negative?}

The paper's maintained hypothesis, that social interaction is stronger in denser areas, arose from the conjecture that high densities facilitate interaction by putting people in close proximity. The results, however, show the opposite effect, and a question is why. One possibility is that dense environments offer residents more sources of entertainment (museums, theaters, etc.), lessening the need to interact with others in the pursuit of stimulation. ${ }^{19}$ Alternatively,

the crowding associated with a dense environment might spur a need for privacy, causing people to draw inward. Such behavior could reflect the old saying: "good fences make good neighbors." Another possibility is that high densities may be associated with criminal activity, making people suspicious of one another and reluctant to interact.

The latter conjecture might be testable by including a crime measure in the interaction equation along with density. Comprehensive crime data are not available at the census tract level, but even if they were, the tract crime level must be viewed as endogenous in the same fashion as density (being the result of household's locational choice). As a result, evaluating crime as a root cause of the density effect is not at all straightforward.

Since crime may limit interaction by eroding trust between individuals, an alternative approach would be to include the survey's trust variable as a covariate in the regression along with density (the variable measures the degree of trust that the respondent feels toward others). However, this approach is also problematic. The difficulty is that trust is endogenous, presumably being dependent on life experiences such as crime victimization, which in turn may be a function of density. As a result, trust seems inappropriate as an additional covariate in an equation explaining interaction.

Given this discussion, it appears that isolating the root cause of the negative density effect is a difficult task, one that is beyond the scope of the present paper. Indeed, the message of this paper would be unaffected by the results of any such further inquiry. Whatever the reason, density has been shown to exert a negative influence on social interaction, undermining 
an important line of attack used by critics of urban sprawl.

\section{Conclusion}

Various authors, most notably Putnam (2000), have argued that low-density living reduces social interaction, and this argument has been used to buttress criticisms of urban sprawl. But urban expansion must involve market failures if it is to be inefficient, and this paper shows that such a distortion indeed arises if low density depresses social interaction. Then, in appraising the gains from greater individual consumption of living space, consumers fail to consider reduced interaction benefits for their neighbors, which arise through lower neighborhood density. Space consumption is then too high, and cities are excessively spread out.

The key element in this argument is a positive link between social interaction and neighborhood density, and the paper tests empirically for such a link. The results are unfavorable: whether the focus is friendship-oriented social interaction or measures of group involvement, the empirical results show a negative, rather than positive, effect of density on interaction.

The paper's findings therefore imply that social-interaction effects cannot be credibly included in the panoply of criticisms directed toward urban sprawl. In fact, the results suggest an opposite line of argument. With a negative effect of density on interaction, individual space consumption would tend to be too low rather than too high, tending to make cities inefficiently compact, as explained in section 2. Thus, the empirical results suggest that social-interaction effects may counteract, rather than exacerbate, the well-recognized forces (such as unpriced traffic congestion) that cause cities to overexpand. 


\section{TABLE 1: Variable Definitions}

\section{Dependent variables}

\begin{tabular}{|c|c|c|c|c|}
\hline Variable & Definition & Mean & Minimum & Maximum \\
\hline NEISOC & $\begin{array}{l}\text { How often respondent talks with or visits immediate neighbors: } 1=\text { never, } 2=\text { once a year or less, } 3 \\
=\text { several times a year, } 4=\text { =nce a month, } 5=\text { several times a month, } 6=\text { several times a week, } 7=\text { just } \\
\text { about every day }\end{array}$ & 5.079 & 1 & 7 \\
\hline NEITALK & $=1$ if respondent talks or visits immediate neighbors at least once a week, 0 otherwise & 0.538 & 0 & 1 \\
\hline CONFIDE & Number of people respondent can confide in: $1=$ nobody, $2=0$ ene, $3=$ two, $4=$ three or more & 3.551 & 1 & 4 \\
\hline FRIENDS & $\begin{array}{l}\text { Number of close friends respondent has: } 1=\text { none, } 2=\text { one or two, } 3=\text { three to five, } 4=\text { six to ten, } \\
5=\text { more than ten }\end{array}$ & 3.326 & 1 & 5 \\
\hline FRNDHNG & Number of times per year respondent hangs out with friends in a public place & 16.767 & 0 & 60 \\
\hline FRNDHOM & Number of times per year respondent visits with friends at home & 22.049 & 0 & 60 \\
\hline NEICOOP & = 1 if respondent has worked with neighbors to get something fixed or improved & 0.315 & 0 & 1 \\
\hline GRPHOB & $=1$ if respondent participates in a hobby, investment or garden club & 0.261 & 0 & 1 \\
\hline CCLUBMET & Number of times per year respondent attends club meetings & 6.008 & 0 & 53 \\
\hline GRPINVLV & Number of types of non-religious organizations to which respondent belongs & 3.158 & 0 & 18 \\
\hline
\end{tabular}

\section{Socioeconomic characteristics of respondent}

\begin{tabular}{|c|c|c|c|c|}
\hline Variable & Definition & Mean & Minimum & Maximum \\
\hline MALE & $=1$ if respondent is male, 0 otherwise & 0.411 & 0 & 1 \\
\hline AGE & Respondent's age in years & 44.584 & 18 & 99 \\
\hline AGE2 & AGE squared & & & \\
\hline PART_MAR & $=1$ if respondent is married or living with partner, 0 otherwise & 0.569 & 0 & 1 \\
\hline KIDS6 & Number of children in household under six years old & 0.258 & 0 & 14 \\
\hline KID6_17 & Number of children in household between six and seventeen & 0.475 & 0 & 8 \\
\hline INC2 & $=1$ if $\$ 20 \mathrm{k}<$ annual household income $<\$ 30 \mathrm{k}$ & 0.148 & 0 & 1 \\
\hline INC3 & $=1$ if $\$ 30 \mathrm{k}<$ annual household income $<\$ 50 \mathrm{k}$ & 0.257 & 0 & 1 \\
\hline INC4 & $=1$ if $\$ 50 \mathrm{k}<$ annual household income $<\$ 75 \mathrm{k}$ & 0.201 & 0 & 1 \\
\hline INC5 & $=1$ if $\$ 75 \mathrm{k}<$ annual household income $<\$ 100 \mathrm{k}$ & 0.114 & 0 & 1 \\
\hline INC6 & $=1$ if annual household income $>\$ 100 \mathrm{k}$ & 0.126 & 0 & 1 \\
\hline EDSMCOLL & $=1$ if respondent has completed some college education, 0 otherwise & 0.327 & 0 & 1 \\
\hline EDCOLLGD & $=1$ if respondent has a college degree, 0 otherwise & 0.362 & 0 & 1 \\
\hline RACBLACK & $=1$ if respondent is black, 0 otherwise & 0.147 & 0 & 1 \\
\hline RACHISPN & $=1$ if respondent is Hispanic, 0 otherwise & 0.088 & 0 & 1 \\
\hline RACASIAN & $=1$ if respondent is Asian, 0 otherwise & 0.028 & 0 & 1 \\
\hline UNEMP & $=1$ if respondent is unemployed, 0 otherwise & 0.044 & 0 & 1 \\
\hline RETIRED & $=1$ if respondent is retired, 0 otherwise & 0.161 & 0 & 1 \\
\hline CITIZ & $=1$ if respondent is a US citizen, 0 otherwise & 0.949 & 0 & 1 \\
\hline LIVG5 & $=1$ if respondent has lived in his/her community for more than five years, 0 otherwise & 0.084 & 0 & 1 \\
\hline
\end{tabular}




\section{Population density measures}

\begin{tabular}{|c|c|c|c|c|}
\hline Variable & Definition & Mean & Minimum & Maximum \\
\hline LNPDEN_TRACT & Census tract density: people per square mile & 8.008 & 1.529 & 12.258 \\
\hline LNPDEN_UA & Urbanized Area density: people per square mile & 7.845 & 6.747 & 8.863 \\
\hline LNPDEN_P_MSA & MSA density: people per square mile & 6.188 & 3.281 & 7.615 \\
\hline
\end{tabular}

Regional controls. Omitted category: Pacific

\begin{tabular}{|c|c|c|c|c|}
\hline Variable & Definition & Mean & Minimum & Maximum \\
\hline NEWENGL & $=1$ if census region is New England, 0 otherwise & 0.066 & 0 & 1 \\
\hline MIDATLAN & $=1$ if census region is Mid Atlantic, 0 otherwise & 0.096 & 0 & 1 \\
\hline EANOCENT & $=1$ if census region is East North Central, 0 otherwise & 0.247 & 0 & 1 \\
\hline WENOCENT & $=1$ if census region is West North Central, 0 otherwise & 0.060 & 0 & 1 \\
\hline SOUTHATL & $=1$ if census region is South Atlantic, 0 otherwise & 0.206 & 0 & 1 \\
\hline EASOCENT & $=1$ if census region is East South Central, 0 otherwise & 0.044 & 0 & 1 \\
\hline WESOCENT & $=1$ if census region is West South Central, 0 otherwise & 0.030 & 0 & 1 \\
\hline MOUNTN & $=1$ if census region is Mountain, 0 otherwise & 0.078 & 0 & 1 \\
\hline
\end{tabular}


Table 2: First Stage Regression

Dependent Variable: LNPDEN_TRACT

\begin{tabular}{|l|rr|}
\cline { 2 - 3 } \multicolumn{1}{l|}{} & \multicolumn{1}{l}{ Coef. } & \multicolumn{1}{c|}{ t } \\
\hline MALE & 0.006 & 0.320 \\
AGE & -0.012 & -3.150 \\
AGE2 & 0.000 & 1.920 \\
PART_MAR & -0.179 & -7.760 \\
KIDS6 & -0.034 & -2.630 \\
KID6_17 & -0.028 & -2.190 \\
INC2 & -0.085 & -2.800 \\
INC3 & -0.153 & -5.330 \\
INC4 & -0.276 & -7.780 \\
INC5 & -0.310 & -7.260 \\
INC6 & -0.397 & -7.570 \\
EDSMCOLL & 0.086 & 3.040 \\
EDCOLLGD & 0.221 & 5.440 \\
RACBLACK & 0.507 & 10.210 \\
RACHISPN & 0.385 & 4.770 \\
RACASIAN & 0.138 & 2.420 \\
UNEMP & 0.107 & 2.600 \\
HOMEMAK & -0.035 & -0.750 \\
RETIRED & -0.065 & -1.470 \\
CITIZ & -0.103 & -2.260 \\
LIVG5 & 0.009 & 0.180 \\
NEWENGL & 0.081 & 0.190 \\
MIDATLAN & -0.006 & -0.030 \\
EANOCENT & -0.095 & -0.450 \\
WENOCENT & 0.349 & 2.230 \\
SOUTHATL & -0.412 & -1.560 \\
EASOCENT & -0.391 & -1.540 \\
WESOCENT & -0.320 & -1.400 \\
MOUNTN & 0.134 & 0.870 \\
LNPDEN_UA & 0.656 & 2.890 \\
LNPDEN_P_MSA & 0.482 & 6.300 \\
CONSTANT & 0.517 & 0.330 \\
\hline
\end{tabular}

$N=14827$

Number of clusters (Urbanized Areas) $=308$

R-squared $=0.379 \quad F(31,307)=43.04$ 
TABLE 3: Friendship-Oriented Variables

\begin{tabular}{|c|c|c|c|c|c|c|c|c|c|c|c|c|}
\hline & \multicolumn{2}{|c|}{$A$} & \multicolumn{2}{|c|}{$\mathrm{B}$} & \multicolumn{2}{|c|}{$\mathrm{C}$} & \multicolumn{2}{|c|}{$\mathrm{D}$} & \multicolumn{2}{|c|}{$E$} & \multicolumn{2}{|c|}{$\mathrm{F}$} \\
\hline & \multicolumn{2}{|c|}{ NEISOC } & \multicolumn{2}{|c|}{ NEITALK } & \multicolumn{2}{|c|}{ CONFIDE } & \multicolumn{2}{|c|}{ FRIENDS } & \multicolumn{2}{|c|}{ FRNDHNG } & \multicolumn{2}{|c|}{ FRNDHOM } \\
\hline & \multicolumn{2}{|c|}{ (2SLS) } & \multicolumn{2}{|c|}{ (IVPROBIT) } & \multicolumn{2}{|c|}{ (2SLS) } & \multicolumn{2}{|c|}{ (2SLS) } & \multicolumn{2}{|c|}{ (2SLS) } & \multicolumn{2}{|c|}{ (2SLS) } \\
\hline & Coeff & $\mathrm{z}$ & Coeff & $z$ & Coeff & $z$ & Coeff & $z$ & Coeff & $z$ & Coeff & $z$ \\
\hline LNPDEN_TRACT & -0.081 & -2.51 & -0.024 & -1.48 & -0.020 & -2.14 & -0.027 & -2.37 & -0.419 & -1.36 & -1.086 & -3.38 \\
\hline MALE & 0.054 & 1.61 & 0.027 & 1.13 & -0.102 & -9.50 & 0.060 & 3.27 & -2.358 & -7.79 & 0.111 & 0.36 \\
\hline AGE & 0.024 & 3.35 & 0.010 & 2.10 & -0.009 & -3.80 & -0.023 & -6.41 & -1.400 & -21.73 & -1.243 & -20.76 \\
\hline AGE2 & 0.000 & -1.13 & 0.000 & -0.07 & 0.000 & 3.17 & 0.000 & 6.53 & 0.010 & 15.12 & 0.009 & 13.63 \\
\hline PART_MAR & 0.098 & 2.75 & 0.075 & 2.92 & -0.023 & -1.91 & -0.044 & -2.62 & -5.299 & -15.39 & -2.035 & -5.44 \\
\hline KIDS6 & 0.129 & 5.68 & 0.100 & 5.07 & -0.036 & -3.81 & -0.055 & -3.47 & -1.649 & -5.91 & -0.971 & -4.67 \\
\hline KID6_17 & 0.075 & 3.59 & 0.053 & 4.09 & -0.026 & -3.46 & -0.048 & -4.81 & -0.907 & -5.33 & -0.280 & -1.04 \\
\hline INC2 & 0.023 & 0.36 & -0.035 & -1.13 & 0.106 & 3.84 & 0.131 & 3.97 & 1.218 & 2.24 & 1.129 & 1.78 \\
\hline INC3 & 0.207 & 3.72 & 0.025 & 0.66 & 0.173 & 6.24 & 0.213 & 6.68 & 2.500 & 5.08 & 1.877 & 3.20 \\
\hline INC4 & 0.241 & 3.70 & 0.010 & 0.30 & 0.206 & 7.19 & 0.256 & 7.84 & 3.440 & 5.91 & 2.602 & 3.87 \\
\hline INC5 & 0.257 & 3.55 & 0.011 & 0.23 & 0.219 & 8.10 & 0.271 & 7.58 & 4.404 & 6.23 & 2.591 & 3.10 \\
\hline INC6 & 0.280 & 3.62 & 0.034 & 0.63 & 0.272 & 8.48 & 0.414 & 11.18 & 5.694 & 8.55 & 5.049 & 7.07 \\
\hline EDSMCOLL & 0.120 & 3.04 & 0.065 & 2.85 & 0.149 & 9.46 & 0.115 & 4.91 & 1.699 & 4.75 & 1.044 & 2.36 \\
\hline EDCOLLGD & 0.072 & 1.63 & -0.033 & -1.10 & 0.217 & 14.41 & 0.219 & 7.79 & 1.119 & 2.23 & -0.402 & -0.85 \\
\hline RACBLACK & -0.383 & -7.05 & -0.145 & -4.12 & -0.190 & -8.81 & -0.386 & -12.74 & -2.044 & -4.69 & -2.783 & -5.62 \\
\hline RACHISPN & -0.467 & -6.37 & -0.195 & -3.83 & -0.294 & -11.31 & -0.198 & -5.32 & -1.285 & -1.91 & -3.725 & -5.63 \\
\hline RACASIAN & -0.290 & -3.11 & -0.159 & -2.94 & -0.161 & -3.71 & -0.159 & -3.73 & -2.280 & -3.56 & -2.740 & -2.90 \\
\hline UNEMP & -0.089 & -1.03 & -0.050 & -1.07 & -0.056 & -2.08 & -0.078 & -2.14 & -0.311 & -0.35 & 0.486 & 0.60 \\
\hline HOMEMAK & 0.116 & 1.49 & 0.085 & 1.42 & 0.009 & 0.36 & 0.012 & 0.30 & 0.407 & 0.63 & 0.129 & 0.21 \\
\hline RETIRED & 0.146 & 2.24 & 0.110 & 2.47 & 0.016 & 0.48 & 0.120 & 3.42 & 1.463 & 2.09 & 1.773 & 2.62 \\
\hline CITIZ & 0.475 & 6.11 & 0.310 & 5.72 & 0.121 & 2.93 & 0.036 & 0.92 & 1.437 & 1.85 & 4.202 & 6.28 \\
\hline LIVG5 & 0.087 & 1.47 & 0.028 & 0.74 & -0.015 & -0.77 & 0.095 & 3.27 & 1.183 & 2.13 & 1.886 & 3.17 \\
\hline NEWENGL & -0.181 & -1.59 & -0.091 & -1.27 & -0.010 & -0.61 & -0.096 & -3.95 & -0.335 & -0.54 & 0.351 & 0.42 \\
\hline MIDATLAN & -0.050 & -0.63 & 0.015 & 0.30 & -0.096 & -5.74 & -0.108 & -3.65 & -1.165 & -1.97 & -1.355 & -1.48 \\
\hline EANOCENT & 0.019 & 0.35 & 0.012 & 0.32 & -0.045 & -2.93 & -0.006 & -0.23 & -0.107 & -0.21 & -1.556 & -2.83 \\
\hline WENOCENT & 0.180 & 3.23 & 0.126 & 4.47 & -0.008 & -0.36 & 0.066 & 2.59 & 1.668 & 2.55 & 0.166 & 0.36 \\
\hline SOUTHATL & -0.087 & -1.33 & -0.022 & -0.53 & -0.123 & -6.05 & -0.076 & -2.55 & -2.294 & -3.22 & -3.095 & -5.61 \\
\hline EASOCENT & -0.120 & -1.37 & -0.058 & -1.04 & -0.169 & -5.23 & -0.046 & -1.26 & -1.364 & -1.78 & -3.067 & -3.30 \\
\hline WESOCENT & 0.187 & 2.84 & 0.078 & 1.73 & -0.129 & -5.46 & -0.004 & -0.08 & -0.311 & -0.52 & 0.609 & 0.93 \\
\hline MOUNTN & 0.097 & 0.99 & 0.017 & 0.45 & -0.008 & -0.34 & 0.015 & 0.32 & 0.784 & 1.12 & 1.039 & 1.75 \\
\hline CONSTANT & 4.112 & 11.43 & -0.532 & -2.64 & 3.708 & 34.76 & 3.736 & 28.40 & 60.422 & 18.01 & 62.561 & 19.46 \\
\hline $\begin{array}{l}\text { OLS or Probit Coeff, z } \\
\text { LPDEN_TRACT }\end{array}$ & 0.005 & 0.31 & 0.019 & 1.96 & -0.006 & -1.46 & -0.006 & -1.03 & 0.334 & 2.67 & 0.029 & 0.20 \\
\hline
\end{tabular}




\begin{tabular}{|c|c|c|c|c|c|c|}
\hline & NEISOC & NEITALK & CONFIDE & FRIENDS & FRNDHNG & FRNDHOM \\
\hline $\mathrm{N}$ & 14755 & 14755 & 14804 & 14810 & 14806 & 14802 \\
\hline Number of clusters & 306 & 306 & 308 & 307 & 308 & 308 \\
\hline$F($ d.f. $)$ & $88.42 \quad(30,305)$ & & $115.150 \quad(30,307)$ & $71.99 \quad(30,306)$ & $150.840 \quad(30,307)$ & $206.180 \quad(30,307)$ \\
\hline P-value & 0.000 & & 0.000 & 0.000 & 0.000 & 0.000 \\
\hline Wald Chi-sq (30) & --- & 1707.010 & --- & --- & --- & --- \\
\hline P-value & & 0.000 & & & & \\
\hline Hansen J Statistic & 0.017 & --- & 0.544 & 1.979 & 4.591 & 7.040 \\
\hline Chi-sq(1) P-value & 0.897 & & 0.461 & 0.160 & 0.032 & 0.008 \\
\hline $\begin{array}{l}\text { Endogeneity test of } \\
\text { endog. regressors }\end{array}$ & 7.256 & 9.400 & 2.896 & 3.629 & 3.383 & 7.019 \\
\hline Chi-sq(1) P-value & 0.007 & 0.002 & 0.089 & 0.057 & 0.066 & 0.008 \\
\hline
\end{tabular}


TABLE 4: Group-Involvement Variables

\begin{tabular}{|c|c|c|c|c|c|c|c|c|}
\hline & \multirow{2}{*}{\multicolumn{2}{|c|}{ A }} & \multirow{2}{*}{\multicolumn{2}{|c|}{$\mathrm{B}$}} & \multirow{2}{*}{\multicolumn{2}{|c|}{ C }} & \multirow{2}{*}{\multicolumn{2}{|c|}{$\mathrm{D}$}} \\
\hline & & & & & & & & \\
\hline & \multicolumn{2}{|c|}{ NEICOOP } & \multicolumn{2}{|c|}{ GRPHOB } & \multicolumn{2}{|c|}{ CCLUBMET } & \multicolumn{2}{|c|}{ GRPINVLV } \\
\hline & \multicolumn{2}{|c|}{ (IVPROBIT) } & \multicolumn{2}{|c|}{ (IVPROBIT) } & \multicolumn{2}{|c|}{ (2SLS) } & \multicolumn{2}{|c|}{ (2SLS) } \\
\hline & Coeff & $z$ & Coeff & $z$ & Coeff & $z$ & Coeff & $z$ \\
\hline LNPDEN_TRACT & 0.031 & 1.50 & -0.047 & -2.91 & -0.478 & -2.30 & -0.099 & -2.05 \\
\hline MALE & 0.038 & 1.04 & 0.135 & 5.29 & -0.638 & -2.98 & 0.033 & 0.63 \\
\hline AGE & 0.026 & 4.70 & 0.010 & 2.57 & -0.217 & -6.33 & 0.025 & 2.74 \\
\hline AGE2 & 0.000 & -3.17 & 0.000 & -2.26 & 0.002 & 5.59 & 0.000 & -0.46 \\
\hline PART_MAR & 0.070 & 2.44 & -0.082 & -3.75 & -0.885 & -4.64 & -0.063 & -1.57 \\
\hline KIDS6 & 0.022 & 0.88 & -0.082 & -4.27 & -0.486 & -4.01 & -0.031 & -1.38 \\
\hline |KID6_17 & 0.083 & 4.52 & -0.021 & -1.29 & 0.539 & 3.90 & 0.300 & 11.92 \\
\hline INC2 & -0.020 & -0.37 & 0.016 & 0.37 & 0.499 & 1.87 & 0.254 & 3.58 \\
\hline INC3 & 0.058 & 1.04 & 0.171 & 3.98 & 1.059 & 3.60 & 0.591 & 7.94 \\
\hline INC4 & 0.182 & 3.87 & 0.241 & 6.07 & 1.689 & 5.81 & 0.811 & 12.99 \\
\hline INC5 & 0.257 & 3.82 & 0.309 & 5.56 & 1.331 & 3.98 & 0.978 & 10.15 \\
\hline INC6 & 0.295 & 4.38 & 0.367 & 7.29 & 2.979 & 7.89 & 1.418 & 14.84 \\
\hline EDSMCOLL & 0.184 & 5.76 & 0.279 & 10.54 & 2.214 & 8.25 & 0.897 & 17.21 \\
\hline EDCOLLGD & 0.191 & 5.27 & 0.404 & 12.31 & 3.748 & 13.48 & 1.693 & 27.88 \\
\hline RACBLACK & 0.149 & 3.10 & 0.015 & 0.35 & 0.145 & 0.36 & 0.810 & 8.26 \\
\hline RACHISPN & 0.040 & 0.75 & -0.029 & -0.49 & -0.569 & -1.50 & 0.231 & 2.09 \\
\hline RACASIAN & -0.079 & -0.61 & -0.058 & -0.91 & -1.278 & -1.92 & -0.246 & -1.98 \\
\hline UNEMP & -0.122 & -1.65 & -0.101 & -1.84 & -0.876 & -2.30 & -0.256 & -3.10 \\
\hline HOMEMAK & 0.114 & 1.94 & 0.039 & 0.76 & 0.253 & 0.58 & -0.335 & -3.83 \\
\hline RETIRED & -0.015 & -0.24 & 0.161 & 3.49 & 0.860 & 2.23 & -0.086 & -0.82 \\
\hline CITIZ & 0.307 & 2.79 & 0.142 & 2.38 & 2.180 & 7.91 & 0.662 & 9.26 \\
\hline LIVG5 & 0.112 & 1.93 & 0.010 & 0.25 & 0.965 & 2.37 & 0.080 & 1.06 \\
\hline NEWENGL & 0.131 & 3.52 & -0.065 & -1.26 & -0.544 & -1.37 & -0.127 & -1.18 \\
\hline MIDATLAN & -0.048 & -1.20 & -0.047 & -0.94 & -0.691 & -1.46 & -0.108 & -0.81 \\
\hline EANOCENT & 0.020 & 0.31 & -0.011 & -0.24 & -0.041 & -0.10 & 0.132 & 1.21 \\
\hline WENOCENT & 0.127 & 3.34 & -0.032 & -0.53 & 0.363 & 0.85 & 0.081 & 0.61 \\
\hline SOUTHATL & 0.107 & 2.35 & -0.059 & -1.13 & -0.323 & -0.61 & 0.045 & 0.34 \\
\hline EASOCENT & 0.102 & 0.85 & -0.075 & -1.23 & -0.806 & -1.50 & 0.076 & 0.59 \\
\hline WESOCENT & 0.160 & 2.31 & -0.010 & -0.16 & 0.547 & 1.01 & 0.000 & 0.00 \\
\hline MOUNTN & 0.102 & 2.03 & 0.006 & 0.10 & 0.264 & 0.47 & 0.086 & 0.64 \\
\hline CONSTANT & -2.195 & -9.05 & -1.026 & -5.56 & 10.209 & 5.21 & 0.548 & 1.08 \\
\hline $\begin{array}{l}\text { OLS or Probit Coeff, z } \\
\text { LPDEN_TRACT }\end{array}$ & 0.011 & 0.87 & -0.005 & -0.65 & -0.036 & -0.37 & 0.012 & 0.67 \\
\hline $\mathrm{N}$ & 7316 & & 14813 & & 14794 & & 14827 & \\
\hline Number of clusters & 242 & & 308 & & 308 & & 308 & \\
\hline$F($ d.f. $)$ & --- & & --- & & 40.000 & $0,307)$ & 179.360 & $(30,307)$ \\
\hline P-value & & & & & 0.000 & & 0.000 & \\
\hline Wald Chi-sq ( 30) & 753.610 & & 907.760 & & --- & & --- & \\
\hline P-value & 0.000 & & 0.000 & & & & & \\
\hline Hansen J Statistic & --- & & --- & & 0.049 & & 0.026 & \\
\hline Chi-sq(1) P-value & & & & & 0.825 & & 0.872 & \\
\hline $\begin{array}{l}\text { Endogeneity test of } \\
\text { endog. regressors }\end{array}$ & 0.710 & & 6.990 & & 3.624 & & 4.815 & \\
\hline Chi-sq(1) P-value & 0.399 & & 0.008 & & 0.057 & & 0.028 & \\
\hline
\end{tabular}


Table 5: LPDEN_TRACT Coefficient in Other Specifications

\begin{tabular}{|c|c|c|c|c|}
\hline & \multicolumn{2}{|c|}{ Single Instrument } & \multicolumn{2}{|c|}{\begin{tabular}{|l|} 
W/o PART_MAR, \\
KIDS,HOMEMAKER
\end{tabular}} \\
\hline & Coeff & $z$ & Coeff & $\mathrm{z}$ \\
\hline NEISOC & -0.079 & -2.03 & -0.095 & -2.82 \\
\hline NEITALK & -0.017 & -0.66 & -0.032 & -1.93 \\
\hline CONFIDE & -0.023 & -2.07 & -0.014 & -1.60 \\
\hline FRIENDS & -0.028 & -1.82 & -0.018 & -1.61 \\
\hline FRNDHNG & -0.150 & -0.39 & -0.005 & -0.02 \\
\hline FRNDHOM & -0.717 & -1.97 & -0.912 & -2.87 \\
\hline NEICOOP & 0.029 & 1.05 & 0.023 & 1.11 \\
\hline GRPHOB & -0.055 & -2.35 & -0.360 & -2.27 \\
\hline CCLUBMET & -0.459 & -2.02 & -0.440 & -2.09 \\
\hline GRPINVLV & -0.117 & -1.96 & -0.110 & -2.24 \\
\hline
\end{tabular}




\section{References}

Borck, R., 2006. Social agglomeration externalities. Unpublished paper, DIW Berlin.

Brueckner, J.K., 2000. Urban sprawl: Diagnosis and remedies. International Regional Science Review 23, 160-171.

Brueckner, J.K., 2001. Urban sprawl: Lessons from urban economics. In: Gale, W.G., Pack, J.R. (Eds.), Brookings-Wharton Papers on Urban Affairs, Brookings Institution, Washington, D.C., pp. 65-89.

Brueckner, J.K., 2006. Urban growth boundaries: An effective second-best remedy for unpriced road congestion? Unpublished paper, University of California, Irvine.

Ewing, R., Schmid, T., Killingsworth R., Zlot A., Raudenbush, S., 2003. Relationship between urban sprawl and physical activity, obesity and morbidity, American Journal of Health Promotion 18, 47-57.

Fujita, M., 1989. Urban Economic Theory, Cambridge University Press, New York.

Glaeser, E.L., Kahn, M.E., 2004. Sprawl and urban growth. In: Henderson, J.V., Thisse, J.-F. (Eds.), Handbook of Urban Economics, Vol. IV, Elsevier, Amsterdam, forthcoming.

Glaeser, E.L., Gottlieb, J.D., 2006. Urban resurgence and the consumer city, Urban Studies, forthcoming.

Lopez, R., 2004. Urban sprawl and the risk for being overweight or obese, American Journal of Public Health 94, 1574-1579.

Nechyba, T.J., Walsh, R., 2004. Urban sprawl. Journal of Economic Perspectives 18(4), $177-200$.

Powdthavee, N., 2005. Identifying causal effects with panel data: The case of friendship and happiness, Unpublished paper, University of London.

Putnam, R.D., 2000. Bowling Alone, Simon and Schuster, New York. 


\section{Footnotes}

*We thank Rainald Borck, Ami Glazer, David Neumark, Stuart Rosenthal and Ken Small for helpful comments. They are not responsible, however, for any shortcomings in the paper.

${ }^{1}$ For a good overview of these arguments, see the 12-article symposium published in the Fall 1998 issue of the Brookings Review.

${ }^{2}$ A properly-set UGB is equivalent to a tax in dealing with the first failure. However, Brueckner (2006) shows that a UGB is a poor second-best instrument for dealing with unpriced road congestion.

${ }^{3}$ See Powdthavee (2005) for evidence showing that friendships increase happiness.

${ }^{4} \mathrm{~A}$ potential connection between urban sprawl and obesity, which is thought to arise from high auto usage and thus low exercise in sprawling cities, has been the focus of a number of recent papers (see Ewing et al. (2003) and Lopez (2004)). However, even if low-density living contributes to obesity, there appears to be no externality involved and thus no basis for claiming that the effect contributes to an inefficient spatial expansion of cities.

${ }^{5}$ In providing sensitivity analysis in his regressions relating social capital to city size, Borck (2006) presents IV results that treat city size as endogenous. His instrument is lagged city size.

${ }^{6}$ Interaction may have social value as well as generating private benefits. For example, interaction may insure the beneficial spread of information or foster socially responsible behavior. In this case, the average level of interaction in the city could enter individual $i$ 's utility function along with $I_{i}$. However, since interaction is constant across people under the above assumptions, this modification would have no effect on the model.

${ }^{7}$ In Fujita's model, the density effect arises from the negative environmental impact of crowding.

${ }^{8}$ Since the equation predicting tract density is estimated jointly with the interaction equation in the maximum likelihood IVPROBIT routine, the coefficients and standard errors differ slightly from those in Table 2.

${ }^{9}$ To test for validity of the instruments, the probit equation was reestimated as a linear 
probability model using 2 SLS. The J-test failed to reject the overidentifying restrictions.

${ }^{10}$ The age effect turns positive beyond the quadratic minimum at 44 years.

${ }^{11}$ The age effect turns positive beyond 69 years.

${ }^{12}$ The age effect turns positive beyond 69 years.

${ }^{13}$ The age effect turns negative beyond 67 years.

${ }^{14}$ In a 2SLS linear probability model, the J-test did not reject the overidentifying restrictions.

${ }^{15}$ The age effect turns negative beyond 51 years.

${ }^{16}$ In a 2SLS linear probability model, the J-test did not reject the overidentifying restrictions.

${ }^{17}$ The age effect turns positive beyond 53 years.

${ }^{18}$ Glaeser and Gottlieb's study relies on the DDB Needham Life Style Survey, while Borck's uses data from the German Socio-Economic Panel.

${ }^{19}$ Glaeser and Gottlieb (2006) present results showing how participation in various outside entertainment activities is greater in central cities than in suburbs. 